fever. Slight if any desquamation followed. Some days afterwards I found the temperature subnormal, and learning from the patient that she had been previously chilly I told her that she was probably not following out the thyroid treatment with sufficient regularity. Now the patient had been under my own care with severe facial erysipelas four years previously and twice within the same year and once again two years later had had attacks similar to that already mentioned but milder in character. She dated the commencement of her progressive illness from a period about three or four months antecedent to the attack of erysipelas. After exposure to cold she began to suffer from cough, pain in swallowing, and a feeling of suffocation, starting from the midriff and extending over the front of the chest, which rendered inspiration oppresive and difficult. She afterwards complained that I paid little attention to these symptoms; and, indeed, finding them persist without any adequate cause being revealed by auscultation $I$ had come to regard them as hysterical, for I knew that she had a certain alloy of this temperament. On inquiry at a later period it was found that the pain in deglutition was seated over the thyroid in front and that the same spot had been painful on pressure. It should be observed that the patient always spoke of this part as the "throat" which is often used to denote the whole front of the neck. The difficult deglutition which ensued later was referable to two localities, one being the fauces, where it was due to sluggish muscular action, and the second the site of the thyroid. A later symptom worthy of note was a stinging pain in the left iliac region which radiated backwards towards the sacrum and down the inner aspect of the thigh as far as the foot and was apparently of ovarian origin. This came on several months before myxœdema was diagnosed and had become so severe that it was the principal cause of bringing her to me at that time. She also suffered from tremors, vertiginous attacks at night, and felt as if she "were going out of her mind" and becoming incompetent for the duties of life. It is obvious that all these symptoms might be referred to hysteria; if so, the important conclusion seems to follow that hysteria itself in this case was dependent on thyroidal irritation, for all the patient's troubles vanished under thyroid treatment and are apparently only kept at bay by it, for they threaten at once to return whenever it is left off for a short time.

I now incline to the view that thyroidal inadequacy was the predisposing and all-important cause both of the erysipelas and urticarial attacks, for which latter no error in diet or drug or other source of irritation could be discovered. The influence of heredity and constitutional states in these affections is worthy of notice in this connexion and it soon appeared that the former had its share in this case also so far as the myxœdema was observed. No sooner had the patient experienced the benefit of the thyroid treatment than she expressed her conviction that a married sister living in Ardrossan must be the subject of the same disease. On visiting the latter I found it was even so; she was already, at the age of 50 years, in an advanced stage, with great impairment of the mental faculties, besides being nearly deaf and blind. I left her for thyroid treatment under the care of Dr. J. McDonald who lately reported that the swelling had disappeared except over the abdomen and that there was improvement in hearing, physical capacity, and mental powers. I cannot detect any trace of the thyroid in Case 2 and she cannot do without a thyroid tabloid for more than a few days, while Case 1 can sometimes dispense with the remedy for a month. Both are positive in asserting that there never was any swelling in the region of the gland. Nevertheless, do not these cases lend some countenance to the supposition that besides sudden and violent perturbations of thyroidal function there may be such an affection as an acute thyroiditis which may sometimes be the starting-point of atrophy and fibrosis?

Glasgow.

MONTGOMERYSHIRE INFIRMARY.-The annual general meeting of governors was held at Newtown on Feb. 23rd, Mr. R. E. Jones presiding. The board of management reported that the adverse balance had increased during the year from $£ 96$ to $£ 214$ in consequence of the additional accommodation provided for special cases. The medical staff was re-elected and on the motion of Mr. Harold Palmer, seconded by Mr. J. C. Gittins, Dr. Edward Oureton (Shrewsbury) was appointed an honorary consulting physician of the institution.

\section{INJURY TO THE VAGINA, THE RECTUM, AND THE PELVIS;}

SUBSEQUENT NECROSIS OF THE PUBES AND PREVESICAL ABSCESS ; OPERATION ; RECOVERY.

BY H. BETHAM ROBINSON, M.S. LOND., F.R.C.S. ENG., ASSISTANT SURGEON TO, AND SURGEON FOR DISEASES OF THE THROAT AT, ST. TH MONDON HOSPITAL FOR CHILDREN, SHADWELL.

THE following case merits attention from the unusual sequel of a crushing injury to the pelvis and soft parts.

A girl, aged 10 years, was admitted into St. Thomas's Hospital under my care on August 10th, 1895. When crossing the road on that day she was knocked down by an omnibus, the front wheel passing over her lower abdomen. On admission she complained of intense pain above the pelvis and there was considerable bleeding from the vagina. On examination under ether it was discovered on separating the labia that the mucous membrane of the vagina had retracted upwards, being completely torn away round its orifice but behind the hymen below: the wound here was complicated by a rent in the recto-vaginal septum. Owing to the retraction of the vagina there was distortion of the urethra but apparently there was no wound in it. There was no evidence of any fracture of the pelvis in the way of abnormal mobility and there was no blood in the urine when drawn off with a catheter.

The retracted vagina was brought down and its margins were stitched with silk, as far as possible in their original site; thus the orifice of the urethra was replaced in its natural position. At the lower part where the rectum was rent this was sewn up but the wound was only small.

The notes of the case for August 12th state that since the accident the patient had had retention of urine, and that the urine had to be drawn off by catheter, some difficulty presenting, however, owing to the swelling of the parts. The wound on that date looked very sloughy, but there was no tension. The temperature varied between $100^{\circ}$ and $101.8^{\circ} \mathrm{F}$. The patient was put into a boric lotion bath. On the 14th the temperature still ranged from $100^{\circ}$ to $101 \cdot 8^{\circ}$ The urine was now passed naturally into the bath without pain. The wound was cleaner. On the 15 th there was a reduction of the temperature to below $100^{\circ}$ : there were fæces in the vaginal wound. On the 19 th the patient was making satisfactory progress. There was still a small quantity of fæces in the vagina. The temperature was about the normal line. The wound was much cleaner and was granulating. A number of bruises over the left hip were apparent. On the 31st the bath was discontinued as the wound was now cleaner and was granulating nicely. No fæces passed into the vagina and there was only a little discharge from the vagina. There was no pain. The general condition of the patient was very good. She left the hospital on Sept. 11th with the wound entirely healed; both urination and defecation were performed without any hindrance.

On April 20th, 1898, the patient was again brought up to the hospital complaining of having experienced severe pain for the past three days in the lower abdomen which was swollen, and there was some difficulty in micturition. The temperature was $1028^{\circ}$ and the child looked decidedly ill. On examination on the 21st there was a hard, rounded swelling on the left side of the mid-line below the umbilicus and per rectum this was felt to be nodulated and elastic, evidently containing fluid and reaching down to the level of the bottom of Douglas's pouch. The genitals gave evidence of the old injury. The lower part of the vestibule was a contracted fibrous ring into which the little finger would not go; the urethral orifice was within this and after some difficulty a small catheter was passed into the bladder, drawing off urine but without influencing the size of the swelling although it did not seem quite so prominent. As the instrument went in it was felt to pass over, as it were, tough fibrous ridges transversely placed on the upper wall about the neck of the bladder. In the vagina a sequestrum about three-quarters of an inch long was discovered and it was removed; it was a portion of the descending ramus of the pubes.

As the swelling seemed probably an abscess in front and to the left side of the bladder, a sequel of her previous accident, an operation was at once proceeded with, the 
patient's temperature at the time being $100 \cdot 6^{\circ}$. An incision was made on the left side starting just above the pubes and at the outer margin of the rectus and passing along the line of the inner half of the inguinal canal. On dividing the external oblique the round ligament was exposed and it was seen to be imbedded in inflammatory infiltration. On cutting carefully through this matted tissue just above the ligament into the floor of the canal a carity was opened of about the size of an orange from which very foetid pus escaped with three small sequestra. The cavity had rather thick, welldefined walls and its floor was over and included the upper part of the left pubic arch and lay above and to the left side of the urethra as proved by the passage of the catheter. In the bone were some small pits from which the sequestra had come. The space was washed out with boric lotion and a drainage-tube was put in. It was dressed with cyanide gauze. The purulent collection was situated in the prevesical space (cavum Retzii) above the superior layer of the triangular ligament and to the left side of the urethra and had formed in relation with the necrosis of the arch secondary to the injury. The sequestrum found in the vagina had exfoliated from the pubes below the inferior layer of the ligament and thus the attachment of both layers of the ligament separated the sites of the necrosing fragments and accounted for the non-communication of the vagina with the abscess cavity.

The after progress of the case was uneventful. The temperature immediately dropped to normal and there was no further interference with micturition. The drainage-tube was removed on April 29th and the child went out with the wound healed on May 4th.

The first point to comment upon is that at the time of the injury, although it was strongly suspected, there was no evidence of any fracture of the pubic arch. In the light of what happened it is highly probable that there was a fissure with some splitting of bone which slowly exfoliated. This necrosis was attended by the formation of the very localised tumour in the front of the bladder. It was curious how the superior layer of the triangular ligament separated the two necrosed fragments and completely shut in the pus collection below.

Upper Wimpole-street, $\mathbf{w}$.

\section{VANISHING TUMOURS. ${ }^{1}$}

\section{Bx D'ARCY POWER, F.R.C.S. ENG.}

SURGEON TO PHE VICTORIA HOSPITAL FOR CHILDREN, CHULSEA ; ASSISTANT SURGEON AND TEACHER OF SURGERY AT S'T. BARTHOLOMEY'S HOSPITAT

I WISH to deal in this paper with a phenomenon which has not yet, I think, received adequate attention though it must have been repeatedly observed by nearly every surgeon. The phenomenon to which $I$ refer is the disappearance of a tumour which sometimes takes place after such slight surgical operations as incision, puncture, or even simple exposure. For the sake of convenience I venture to speak of these swellings as "vanishing tumours," for this character of spontaneous disappearance is really very startling and though it is satisfactory to the patient it is somewhat disconcerting to the medical practitioner for it nearly always falsifies his prognosis.

I would say at the outset that a "vanishing tumour" is not to be confused in any way with a phantom tumour, for it is in every respect a true swelling, visible to the eye, apparent to the touch, and capable of exposure by the ordinary surgical methods; occurring at any age and in either sex; most often innocent but sometimes, as I hope to show, undoubtedly malignant. My attention was first called to this form of tumour by the following case.

CASE 1.-A boy, aged eight years, was brought to me a few years ago suffering from a large cystic lymphangioma which occupied the whole of the left side of the neck, reaching upwards behind the pinna of the ear, the lobule of which it had invaded, and extending across the middle line in front of the neck. The swelling had been noticed directly after birth and it had been tapped before $I$ saw it about 150 times with a trocar and cannula. It had not

l A paper read before Harveian Society of London on March 2nd, undergone much change in size and though it did not increase proportionately to the growth of the boy it got no smaller. The tumour consisted of an elastic and slightly lobulated tissue to which the skin was closely adherent. It clearly contained many cysts varying greatly in size and tenderness. With a full appreciation of the difficulties to be encountered I advised that the tumour should be removed and in due course I extirpated as much of it as lay in the posterior triangle of the neck. The wound healed by first intention and without any trouble except for a sharp attack of lymphangitis about a fortnight after the operation, due to a long railway journey home in frosty weather.

I saw the boy two months after the operation and found that the posterior triangle was free from growth but that the tumour still extended obliquely from the lobe of the ear which it involved, tilting it upwards across the neck to the second or third ring of the trachea on the right side. The swelling was greater at the lower than at the npper part of the neck. Five months after the operation the boy had a second attack of lymphangitis in the tumour and in the following month he had a third attack. After each attack the swelling seemed smaller. He was brought to me again nine months after the operation with the information that the tumour had vanished. I examined the neck carefully and found that the left anterior triangle was so soft that the beating of the carotid artery could be clearly felt and there was no trace whatever of the former swelling. I have seen the boy several times since, but there is no return of the tumour and the two sides of the neck are now quite symmetrical.

Microscopical examination of the piece of tumour removed showed that it consisted of a number of cysts formed of dilated lymphatics. The cysts had no very definite walls and irregular tags of connective tissue projected into them in many places. I should not have been at all surprised therefore if the tumour had consolidated into a mass of fibrous tissue or if the many small cysts had fused into a single large one. But I was distinctly taken aback, though the sensation was a pleasurable one, to find that the swelling, which was of very considerable size and extremely unsightly, had vanished so completely as to leave healthy and supple skin without any underlying induration.

CASE 2.-This case is an equally remarkable one and does not seem to be easily capable of an explanation. A girl, aged one year and ten months, was admitted into the Victoria Hospital for Children at Chelsea under the care of my colleague, Dr. J. W. Carr, on Nov. 1st, 1898. She had been ailing for six months, suffering at first from whooping-cough and afterwards from bronchitis and diarrhœa. During the week before her admission to the hospital she had been getting worse, being feverish, sick, and passing darkcoloured and slimy motions which contained blood, whilst for the last day or two her mother had noticed that she had been getting yellow. The other children were healthy and there was no history of syphilis to be obtained, but a brother and a sister of her mother-i.e., an uncle and an aunt of the patient-are patients in the Brompton Hospital for Consumption. The ward-note states that on admission the child was fairly well nourished, with a paleyellow complexion and yellow conjunctivæ, the skin of the body generally being rather pale. The liver was enlarged and a little tender and its edge could be felt about an inch below the costal margin. All the other organs appeared to be bealthy. The temperature was $1022^{\circ} \mathrm{F}$. Four days later the jaundice was deeper, the abdomen was distended, and the liver was rather larger, for it now reached about one and a half inches below the costal border of the ribs, the upper limit of the liver dulness being on a level with the sixth rib. After an interval of another four days a note was again made that the liver was considerably larger, for its lower border could be felt just above the level of the umbilicus, the upper limit being, as before, in the sixth space. The stools were almost white, but they were less offensive than they had been. Three days later, on Nov. 11th, the liver was said to be still larger, and it was undoubtedly tender when pressure was made over it. The upper limit was the sixth rib, the lower border was on a level with the umbilicus or a little below it. The stools were formed and were of the colour of white clay. The temperature was becoming hectic, oscillating between $102^{\circ}$ and normal. On Nov. 15th, and again on Nov. 18th, the notes repeat the statement that the liver maintained its large size and that the jaundice was still present. The child was handed over for surgical treatment on Nov. 22nd in the 